\title{
A memória des-figurada de Walter Benjamin
}

\section{The dis-figured memory of Walter Benjamin}

\section{La memoria des-figurada de Walter Benjamin}

iD Helano Jader Ribeiro

Universidade Federal de Santa Catarina (UFSC), Florianópolis, Santa Catarina, Brasil. hjcribeiro@gmail.com

Errata: A correção deste artigo foi publicada em 22 de outubro de 2020. https://www.revistas.ufg.br/sig/article/view/64316/35031

Este artigo foi atualizado.

\section{https://www.revistas.ufg.br/sig/article/view/64316/35031}

Resumo: Este artigo propõe uma análise de Walter Benjamin a partir de seus escritos supostamente autobiográficos, Infância berlinense: 1900 e Crônica berlinense, a partir de uma imagem que Freud nos coloca: a do arqueólogo, ou, aquele que escava as memórias. Assim, esse arqueólogo do instante se apresenta pela e na des-figuração de uma linguagem que já surge menos como meio de transmissão da comunicação do que como espaço onde seus sonhos e devaneios se revelam. Por fim, a potência dos Denkbilder benjaminianos se mostra como sintoma de uma modernidade sem norte e como falsa promessa da história da racionalidade e do progresso.

Palavras-chave: Walter Benjamin. Sonho. Infância. Autobiografia.

Abstract: This article proposes an analysis of Walter Benjamin from his supposedly autobiographical writings Berlin Childhood: 1900 and Berlin Chronicle from a figure which Freud puts to us: that of the archaeologist, or, according to psychoanalysis, the one who digs out the memories. 
Thus, this archeologist of the moment presents himself by and in the dis-figuration of a language that already appears less as a means of transmitting communication than as a space where his dreams and daydreams are revealed. Finally, the power of the Benjamin Denkbilder is shown as a symptom of a modernity without a north and as a false promise of the history of rationality and progress.

Keywords: Walter Benjamin. Dream. Childhood. Autobiography.

Resumen: Este artículo propone un análisis de Walter Benjamin a partir de sus escritos supuestamente autobiográficos. Infancia en Berlín hacia el mil novecientos y Crónica De Berlín a partir de una imagen que Freud nos coloca: la del arqueólogo, o aquel que excava las memorias. Así, ese arqueólogo del instante se presenta por la y en la des-figuración de un lenguaje que ya surge menos como medio de transmisión de la comunicación que como espacio donde sus sueños y devaneos se revelan. Por fin, la potencia de los Denkbilder benjaminianos se muestra como síntoma de una modernidad sin norte y como falsa promesa de la historia de la racionalidad y del progreso.

Palabras clave: Walter Benjamin. Sueño. Infancia. Autobiografía

Submetido em 14 de maio de 2019.

Aceito em 27 de novembro de 2019.

Publicado em 04 de abril de 2020. 


\section{Imagens, no entanto, imagens dialéticas}

A anamnese libera as imagens de pensamento do seu enclausuramento a partir do momento da escavação e resgate dos fragmentos, cacos, restos da memória. Essa mesma anamnese não é uma ação passiva, submissa. No processo de restauro do passado, ela se revela potente e transformadora do presente. A escavação arqueológica ( $\dot{p} \chi \eta^{\prime}$, que tanto pode significar "origem" quanto "poder"), no entanto, desenterra com frequência o feio, o abjeto, aquilo que o tempo-de-aqui-agora insiste em não mostrar: seu rosto saturnino, melancólico.

Esses mesmos anjos caídos, oriundos das ruínas e dos destroços, pouco se conformam com certo estado de acédia; ao contrário, anseiam alegoricamente por iluminações redentoras, profanas. Nessa mesma lógica, as imagens de pensamento de Walter Benjamin postulam uma teoria da modernidade que se mostra desencantada com a ordem de chrónos. Ela é, ao mesmo tempo, revolucionária e sua força vem do fragmento enquanto peça de não totalidade, enquanto abertura.

O jogo benjaminiano de escavação da matriz primeva (Ur) dá-se a partir de um movimento que desalinha chrónos e coloca em cena kairós como tempo de intensidades; esse deslocamento só é possível pelo salto (Sprung) dialético executado por Benjamin que, a contrapelo, dilacera o tempo contínuo. Em seu Livro das passagens [Passagenwerk] nos diz:

Origem [Ursprung] - eis o conceito de fenômeno originário transposto do contexto pagão da natureza para os contextos judaicos da história. Agora, nas Passagens, empreendo também um estudo da origem. Na verdade, persigo a origem das formas e das transformações das passagens parisienses desde seu surgimento até seu ocaso, e a apreendo nos fatos econômicos. Estes fatos, do ponto de vista da casualidade, ou seja, como causas não seriam fenômenos originários; tornam-se tais 
A memória des-figurada de Walter Benjamin

Helano Jader Ribeiro

apenas quando, em seu próprio desenvolvimento um termo mais adequado seria desdobramento fazem surgir a série das formas históricas concreta das passagens, assim como a folha, ao abrir-se, desvenda toda a riqueza do mundo empírico das plantas. (BENJAMIN, 2006, p. 504).

Essas imagens não são dialéticas por acaso. Benjamin pensava no poder que as imagens exerciam, sobretudo com os avanços do capitalismo e do consumo. De certa forma, elas surgiam em consonância com o que era visto nas vitrines em sua aparição mais fantasmática, se convertendo não somente em sonho, mas também em desejo: Wunschbilder.

Há, no entanto, uma diferença crucial nessas imagens: o elemento surrealista e revolucionário. Tal assertiva fica perceptível no livro das Passagens: "Mais uma vez, Benjamin assume uma temática surrealista nesta etapa do seu livro das Passagens estabelecendo uma conexão entre a imagem dialética e o sonho"1 (TIEDEMANN, 1973, p. 156). Claro, a ideia aqui apresentada entre imagem e sonho não diz respeito ao apelo fetichista do consumo, mas à quimérica revolução surrealista de um artista que explora seu desejo de politização da estética.

Essas imagens são também da ordem dos habitantes dos limiares (Schwellen)², talvez mais que das fronteiras: "O limiar, todos os limiares, transformam-se, assim em lugares de vida e de pensamento escrito, enquanto a fronteira acabaria por ser, para Benjamin, lugar de morte" (BARRENTO, 2013, p. 124). São essas as imagens dos personagens outsiders da modernidade: o transeunte das galerias e passagens da capital das luzes, que não consome, mas observa, em devaneios, consumidores; a prostituta, que é, ela própria, objeto de consumo; o trapeiro, figura excluída do capitalismo, que cruelmente recolhe os restos de sonhos descartados.

\footnotetext{
1 Noch einmal nimmt Benjamin auf dieser Stufe der Passagenarbeit ein surrealistisches Motiv auf, indem er eine Verbindung zwischen dialektischen Bild und Traum installiert. [As citações em sua língua original aparecerão em notas de rodapé e as traduções apresentadas no corpo do texto são de minha autoria]

2 Assim como o próprio Benjamin, que se exilou e morreu no ano de 1940, em Port-Bou, na fronteira da Espanha com a França: "Mais que nunca Benjamin é um homem de fronteira, figura instável no limiar da história" (BARRENTO, 2013, p. 27).
} 
A memória des-figurada de Walter Benjamin Helano Jader Ribeiro

A força dos Denkbilder benjaminianos não é nada menos que sintoma de uma modernidade desnorteada e desiludida com aquilo que a racionalidade e o progresso não puderam cumprir em suas promessas. Este artigo se propõe, então, à investigação dessa des-figuração [Ent-stellung] imagética na linguagem, aqui revelada menos como meio de transmissão [Mittel] da comunicação do que como espaço [Medium] onde seus sonhos e devaneios despertam [erwachen] em forma de possibilidade de experiência.

\section{Arqueologia do sonho}

As pesquisas e discussões críticas para uma teoria da memória em Walter Benjamin são as mais variadas. Em seu livro Archäologie des Erinnerns. Sigmund Freund in Walter Benjamins Berliner Kindheit (Arqueologia da recordação. Sigmund Freud em Infância berlinense de Walter Benjamin), Nadine Werner detecta que no

[...] fim dos anos 80 dá-se início a discussão com a temática da memória, em que ela, sobretudo, mostra-se frutífera para as pesquisas de sua poética e de sua apropriação da história. Isto diz respeito, principalmente, aos apontamentos das Passagens, às teses histórico-filosóficas, aos textos sobre Proust e às memórias de infância. ${ }^{3}$ (WERNER, 2015, p. 10).

Não por acaso, crítica e pesquisa sobre a temática da memória em Benjamin se direcionam prontamente para seus apontamentos sobre Marcel Proust, associando-os às diferentes perspectivas teóricas entre a concepção de tempo benjaminiana e da recorrente leitura de Em busca do tempo perdido, a partir da teoria de Henri Bergson em Matéria e memória. ${ }^{4}$ É mais frutífero dizer que essa mesma oposição Benjamin-Bergson se funda, sobretudo, na leitura de

\footnotetext{
3 Ende der 1980er Jahre beginnt die Auseinandersetzung mit der Erinnerungsthematik, indem sie vor allem für Untersuchungen seiner Poetik und seiner Geschichtsaneignung fruchtbar gemacht wird.

4 Benjamin toma distância do trabalho de memória de Proust sobretudo na sua Crônica berlinense. Assim, ele se posiciona contra o autor do tempo perdido e seu procedimento de preencher os espaços vazios da memória e de prolongar até o infinito a recordação (Bergson). Benjamin, por sua vez, trabalha com fragmentos condensados como pequenas ruínas no processo da escrita, de modo que ele desfia a linha da memória pelo fragmento como mecanismo de intensificação do passado, um tempo que não segue uma linearidade, mas se propaga trazido-depois (nachträglich).
} 
A memória des-figurada de Walter Benjamin

Helano Jader Ribeiro

tempo e memória de Benjamin sobre Freud. Benjamin já a sugeria, por exemplo, no citadíssimo ensaio de 1929,"A imagem de Proust", revelando, muito sorrateiramente, no referido texto, que toda "interpretação sintética de Proust deve partir necessariamente do sonho"5 (BENJAMIN, 1996, p. 39). Brinco com a citação, afirmando que toda interpretação sobre Proust e a questão da memória ${ }^{6}$ de Walter Benjamin devem partir necessariamente de Freud.

Burkhardt Lindner, em seu livro Studien zu Benjamin (Estudos sobre Benjamin), foi um dos primeiros a apresentar um texto sobre Benjamin, investigando a presença do pensamento de Freud em sua obra. No entanto, essa pesquisa é apenas um panorama geral, em que a temática da memória é pouco levada em consideração pelo autor. O livro de Jutta Wiegmann, de 1989, Psychoanalytische Geschichtstheorie. Eine Studie zur Freud-Rezeption Walter Benjamins (Teoria da história psicanalítica. Um estudo da recepção de Freud em Walter Benjamin), também contempla parcialmente a questão da memória e propõe, principalmente, traçar uma analogia do trabaIho de Freud sobre a teoria do recalque e a filosofia da história de Benjamin.

É possível que um dos obstáculos para uma ligação mais objetiva entre Benjamin e Freud seja o fato de o primeiro citar o último fortuitamente. Sigrid Weigel também aponta para esse embaçamento teórico entre Benjamin e Freud e vê como um problema "a leitura de Benjamin dos escritos freudianos para ser reconstruída, precisamente porque ele raramente se refere explicitamente ou relata sobre eles"7 (WEIGEL, 1997, p. 38).

\footnotetext{
5 Também não é coincidência falarmos aqui em sonho e associarmos a Freud. Houve um ponto de inflexão na Escola de Frankfurt em que as pesquisas começaram a seguir uma linha mais psicanalítica, uma vez que seus teóricos queriam fugir de certa vertente mais tradicional do marxismo. De acordo com Martin Jay: "A tentativa do Institut für Sozialforschung de introduzir a psicanálise em sua teoria crítica neomarxista foi um passo ousado e pouco convencional, que assinalou o desejo do Institut de deixar pra trás a antiga camisa-de-força marxista." (JAY, 2008, p. 134). Benjamin, por sua vez, procura esse balanço pelo tão discutido viés messiânico. A psicanálise pode ser configurada como mais um contrapeso do chamado marxismo evolucionista, vulgar no pensamento de Walter Benjamin.

6 É necessário lembrar, na segunda parte do ensaio "Sobre alguns motivos na obra de Baudelaire", as considerações de Benjamin sobre uma espécie de suspiro final do romance moderno, em se transmitir experiência, levado a cabo por Proust em seu À la recherche du temps perdu. Como o próprio nome nos mostra, esse ensaio não é, necessariamente, sobre Proust, mas Benjamin se limita a discutir algumas questões da memória em Proust. É sabido que, no texto "O narrador", Benjamin aponta para o romance moderno como um projeto de vivência (Erlebnis) em detrimento da experiência (Erfahrung) em vias de extinção. No entanto, a mémoire involontaire de Proust conseguia, mesmo que de forma mecânica, conservar o tradicional ato de se contar e transmitir histórias: "Os oito volumes da obra de Proust dão uma ideia do que seria necessário para restituir ao presente a figura do contador de histórias" (BENJAMIN, 2015, p. 110).

7 Benjamins Lektüre Freudscher Schriften genau zu rekonstruieren, da er nur selten explizit auf diese verweist oder davon berichtet.
} 
A memória des-figurada de Walter Benjamin

Helano Jader Ribeiro

Falamos aqui não somente da mera apreensão de conceitos freudianos por parte de Benjamin e a sua consequente leitura em textos teóricos, ${ }^{8}$ mas, muito além, trata-se da elaboração de uma constelação de imagens (pensemos aqui nas da infância, nas de Rua de mão única, nas Passagens) que tocam muito de perto o universo dessas mesmas Denkfiguren de Freud.

Uma dessas imagens é, sem dúvida, a figura do arqueólogo, imagem de pensamento que encontramos no fragmento "Escavar e recordar". A chave é simples: tal figura de pensamento é a do arqueólogo que escava na terra e tenta se aproximar do passado como alguém que desenterra imagens de sua memória visando à recordação do seu próprio passado: “quem procura aproximar-se do seu próprio passado soterrado, tem de se comportar como um homem que escava" (BENJAMIN, 2013, p. 101). Essas imagens são fragmentos, restos arqueológicos de coleções passadas não plenas, mas que, ainda assim, podem ser desenterradas, revelando-se como traço ${ }^{9}$ do todo. Elas estão carregadas de sentido, mas livre das amarras da totalidade. ${ }^{10}$

Freud também tinha, com frequência, na essência de seu pensamento, o tropo da figura do arqueólogo/analista que desenterra fragmentos de memória soterrados por traumas, choques, recalques. Ele tratava da sua admiração pela arqueologia desde o início de suas indagações sobre a psicanálise, em especial por Heinrich Schliemann, arqueólogo entusiasta que buscou a cidade de Troia basicamente usando como guia uma edição da llíada de Homero. 8 Um dos aspectos mais intrigantes em se analisar a escrita flutuante de Benjamin é o fato de seu pensamento não se resumir
nem a uma sistematização orientada por objetos, assuntos, nem por conceitos. Entretanto, ao mesmo tempo, todos esses
aspectos, se submetem e se posicionam numa lógica que é da ordem da imagem dialética.
9 Analisemos aqui o conceito de "traço" de Jacques Derrida. Para que não saiamos da metáfora do arqueólogo, pensemos no
trabalho de escavação e descoberta de fósseis de animais extintos. Cada osso, cada peça/traço remonta a uma totalidade, mas
ainda assim essas mesmas estruturas estão à espera de sua doação de sentido. O conceito de différance de Derrida nos coloca
o diferimento como um conceito tempo-espacial. Nesse espaçamento, intervalo, locus da memória benjaminiano, surge uma
rede de disseminações de sentido, em que se mostra o traço. É, pois, nesse limiar de pensamentos que o conceito de traço
dialoga com a questão aurática benjaminiana, se a analisarmos como um Medium da memória. A aura, nesse lugar, provoca
"um olhar que deixaria à aparição o tempo de se desdobrar como pensamento, ou seja, que deixaria ao espaço o tempo de se
retramar de outro modo, de se reconverter em tempo" (DIDI-HUBERMAN, 1998, p. 149). Dito de outra forma: o traço se revela,
sobretudo, a partir de seu poder de memória e desconstrução da totalidade. Ele é peça do próprio fragmento e imagem incom-
pleta do pensamento (mas cheia de sentido que, por sua vez, encontra-se ansioso por sua ontologização). Talvez a aproximação
maior entre Derrida e Benjamin aqui resida exatamente na análise de Georges Didi-Huberman acerca do conceito de aura
acima citado. Além disso, trata-se de dois autores que operam com os fragmentos, restos, traços, no lugar das totalidades, de
conceitos fechados. Tanto para Derrida e seus arquiconceitos, quanto para Benjamin em seu projeto de inacabamento dos
conceitos, há um por vir no pensamento que é da ordem do pensamento não totalitário.
10 Muito sintomaticamente, o fragmento que se segue ao “Escavar e recordar" nos Gesammelte Schriften e na edição brasileira é intitulado "Sonho". 
A memória des-figurada de Walter Benjamin

Helano Jader Ribeiro

Apesar de uma série de equívocos na carreira, Schliemann foi responsável por métodos de investigação arqueológicos que até hoje são utilizados. Freud relata para o amigo Wilhelm Fließ em 1899:

Profundamente entre todas as fantasias, nos deparamos com uma cena das suas mais primordiais (antes [da idade de] 22 meses) que atende a todos os requisitos e em que todos os enigmas restantes desembocam; que é tudo ao mesmo tempo, sexual, inofensivo, natural, etc. [...]. É como se Schliemann tivesse desenterrado mais uma vez a suposta cidade lendária Tróia." (FREUD, [1986] apud WERNER, 2015, p. 230).

A última frase parece uma reverberação da própria experiência de Freud, agora redescobrindo a realidade de cenas das quais ele já havia duvidado. Ele arma a comparação com o arqueólogo não só pela menção da pesquisa de Schliemann sobre Troia, mas a metáfora do arqueólogo já se encontra naquele lugar "[p]rofundamente entre todas as fantasias", de modo que ele, a partir dessa mesma cena, se põe no lugar daquele que escava usando o mesmo procedimento da arqueologia.

A Gradiva, de Wilhelm Jensen, teria, provavelmente, ficado despercebida na história da literatura se Freud não Ihe tivesse doado sobrevida através do conhecido texto de 1907,12 "O delírio e os sonhos na 'Gradiva' de W. Jensen". Nele, Freud se detém no protagonista, o arqueólogo Hanold, em particular nos seus sonhos e delírios, como já indica no título. Freud estava convencido de que sonhos e delírios eram significativos e interpretáveis, funcionando muito além de convulsões insignificantes ou indecifráveis da vida psíquica.

No que diz respeito aos sonhos, Freud se baseou em crenças populares e narrativas, que, com frequência, descreviam os estados mentais de seus personagens através de sonhos. Assim, a Gradiva surge como uma novela que Ihe serve para exemplificar

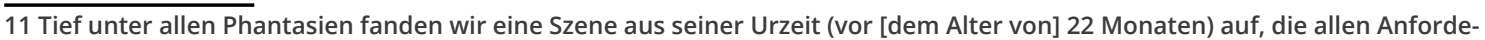
rungen entspricht und in die alle übriggelassenen Rätsel einmünden; die alles zugleich ist, sexuell, harmlos natürlich etc. [...]. Es ist, als hätte Schliemann wieder einmal das für sagenhaft gehaltene Troja aufgegraben.

12 Freud entra em contato com a obra por indicação de Jung. 
A memória des-figurada de Walter Benjamin

Helano Jader Ribeiro

conceitos como os de inconsciente, repressão, translação e outros. Os procedimentos de análise da novela são os mesmos utilizados na sua teoria de interpretação dos sonhos:

Ela consiste em não fazer caso do contexto aparente no sonho manifesto, mas em atentar para cada fragmento do conteúdo e buscar sua origem nas impressões, recordações e pensamentos espontâneos do sonhador. (FREUD, 2015, p. 95).

Sonho e delírio são ambos fontes da ordem do reprimido. Aqueles considerados normais têm sonhos e estes, por sua vez, representam seus delírios fisiológicos. Ou seja, as margens entre normal/anormal se tocam e, muitas vezes, se misturam. Não há nada de desconhecido, estranho, inquietante ou, até mesmo, infamiliar (unheimlich) que não tenha em si algo do já visto [heim, a casa, o lar].

Freud acreditava que os conteúdos do inconsciente podiam voltar ao consciente do sujeito por meio da prática psicanalítica. Benjamin, por outro lado, respeita a impossibilidade de reconstrução total do passado, restando-Ihe somente o sentimento de nostalgia revolucionária.

\section{Pulo primevo à infância}

Quando Benjamin resolve escrever suas memórias através de imagem-sonho-delírios, mesmo que cifrados, não deixa de apontar para a falibilidade da capacidade memorativa. O labor escritural, assim como o processo de memória, recebe uma especial consciência nos textos sobre a infância em Berlim, o que significa dizer que o próprio ato de escrever o passado exige suas condições para partilhar a memória, e assim o faz Benjamin com a dedicação de um esteta da literatura, que se importa menos com o factual do que com uma escrita liberta de si mesma. Segundo Nadine Werner: 
A memória des-figurada de Walter Benjamin

Helano Jader Ribeiro

A memória comenta sempre a si mesma e contém uma densidade e autenticidade que não se alimenta, necessariamente, do mais próximo possível de algo que realmente aconteceu. A relação recursiva de lembrança e escrita é o cenário onipresente para considerar as memórias de infância de Benjamin. ${ }^{13}$ (WERNER, 2015, p. 9, grifo do autor).

Infância berlinense: $1900^{14}$ representa uma complexidade de fragmentos que foram apagados, reescritos, devido ao trânsito em diversas editoras e leituras/correções de Benjamin. Esse conglomerado de textos seguiu uma trajetória que se iniciou em 1926, por ocasião da publicação dos seis primeiros fragmentos da Berliner Chronik - Crônica berlinense, e findou em 1938 com a chamada "versão completa de última mão".

Em Berliner Chronik, Benjamin expressa seu desejo de se afastar de um eu ${ }^{15}$ autobiográfico preocupado em resgatar as memórias íntimas para relatar, também, suas impressões de Berlim. ${ }^{16}$ Em 21 de setembro de 1932, escreve:

Trabalhei muito, desde que aqui cheguei, numa série de anotações [...]. uma espécie de recordações de infância, mas isentas de marcas demasiado individuais ou familiares. Uma espécie de tête-a-tête de uma criança com a cidade de Berlim por volta de 1900. (BENJAMIN, 2013, p. 136).

O fragmento citado nos mostra, então, que esse texto não trata apenas de um resgate nostálgico ou mero relato de escrita de si, mas também do desejo de Benjamin de revelar as reminiscências da cidade natal, de demarcar topologicamente imagens de objetos

\footnotetext{
13 Stets kommentiert sich das Erinnern sich selbst und erhält so eine Dichte und Authentizität, die sich gerade nicht aus der größtmöglichen Nähe zu einem genau so ist es gewesen speist. Das rekursive Verhältnis von Erinnern und Schreiben ist allgegenwärtiger Hintergrund für die Betrachtung von Benjamins Kindheits erinnerungen.

15 A primeira edição de Berliner Kindheit um neunzehnhundert foi organizada por Theodor Adorno no ano de 1950 . Essa primeira compilação contava com diferentes manuscritos de algumas publicações fragmentadas que se juntariam a um outro fragmento. A segunda edição veio à luz em 1972 organizada por Tillman Rexroth e a terceira, publicada em 1987, por Rolf Tiedemann que reuniu uma série de novos excertos encontrados em 1981 por Giorgio Agamben na Bibliothèque Nationale em Paris.

150 eu, nessa lógica, pode surgir somente como gesto, para usar a expressão de Giorgio Agamben a respeito da questão da autoria, e perseguir mais rastros, pegadas (Spuren) que uma verdade cartesiana. Um eu difuso, não captável, não totalizável.

16 No entanto, é contundente a virada cada vez mais literária e poética de Benjamin que parte de Crônica berlinense e chega até Infância berlinense.
} 
A memória des-figurada de Walter Benjamin

Helano Jader Ribeiro

e pequenos afetos num espaço onde sensíveis configurações políticas e sociais ainda conseguiam iluminar seu tempo.

Além da reflexão poética sobre as qualidades da memória, é possível observar também a preocupação de Benjamin em retratar a cidade de Berlim e a burguesia que dela faz parte. Aliás, talvez seu maior desafio seja, exatamente, jogar com a linha tênue entre verdade e invenção (pôr em contato suas margens). Ou seja, fazer crível a leitura social, enquanto faz, ao mesmo tempo, fluir escorregadio pelas amarras da factualidade, sem sacrificar, desse modo, o lirismo de sua escrita. O receio de cair em mero relato confessional pode ser lido nas palavras de Benjamin em Infância berlinense: "Procurei conter esse sentimento recorrendo ao ponto de vista que me aconselhava a seguir a irreversibilidade do tempo passado, não como qualquer coisa de casual e biográfico, mas sim de necessário e social." (BENJAMIN, 2013, p. 69)

A Infância berlinense, de certa forma, poderia ser pensada como uma espécie de cápsula do tempo para os contemporâneos pobres em experiência narrativa e rodeados por mercadorias tecnicamente reproduzidas. O que impede tais imagens de se revelarem como meros relatos pessoais e impressionistas da infância em Berlim é a força messiânica que estes Denkbilder carregam e que podem, assim, realizar o estancamento de uma história contínua e evolutiva. Essas imagens surgem na sensibilidade de seu próprio formato fragmentário. No excerto denominado "A coluna da Vitória"17 lemos:

Assim, quando, em mil novecentos e dois, Ohm Krüger desfilou de carro pela Tauentzienstraße, eu estava com a minha governanta na fila de espectadores, para admirar um senhor que, de chapéu alto na cabeça, se recostava no banco e tinha “conduzido uma guerra". (BENJAMIN, 2013, p. 74).

17 A Coluna da Vitória (Siegessäule) é um dos mais famosos monumentos de Berlim, representada por um anjo. Reinventou-se de símbolo de conquistas militares no século XIX para espaço onde ocorria a Love Parade, festa de música eletrônica que celebrava a diversidade e a liberdade. 
A memória des-figurada de Walter Benjamin

Helano Jader Ribeiro

Esse interessante resgate imagético do general Paul Krüger ${ }^{18}$ (também chamado de tio Krüger) em suas memórias serve como exemplo da trama mnemônica do intelectual exilado que, como o arqueólogo, escava, de uma cena pouco política para uma criança, o relato tácito do que será escrito mais explicitamente no texto de 1940 "Sobre o conceito de história" a respeito da empatia pelos vencedores:

Mas, em cada momento, os detentores do poder são os herdeiros de todos aqueles que antes foram vencedores. Daqui resulta que a empatia que tem por objeto o vencedor serve sempre aqueles que, em cada momento, detêm o poder. Para o materialista histórico não será preciso dizer mais nada. Aqueles que, até hoje, sempre saíram vitoriosos integram o cortejo triunfal que leva os senhores de hoje a passar por cima daqueles que hoje mordem o pó. Os despojos, como é da praxe, são também levados no cortejo. Dá-se-lhes geralmente o nome de património cultural. Eles poderão contar, no materialista histórico, com um observador distanciado, pois o que ele pode abarcar desse património cultural provém, na sua globalidade, de uma tradição em que ele não pode pensar sem ficar horrorizado. (BENJAMIN, 2013, p. 12).

Benjamin, posicionando-se como materialista histórico, coloca pontualmente em questão o historiador de orientação historicista que se compromete com os documentos da cultura que são, como ele bem nos lembra, ao mesmo tempo, documentos de barbárie, e, ao fim do processo, tem o vencedor como objeto de empatia. O trecho "conduzindo uma guerra" está em aspas, porque no relato de Berlim está implícita a ideia de quem é esse vencedor ou "aquele que integra o cortejo triunfal". Esquivar-se desse processo de transmissão da tradição dos vencedores é a via de mão única para, segundo o método benjaminiano, escovarmos a história a contra-

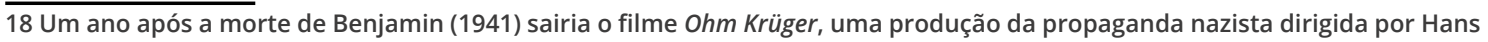
Steinhoff e protagonizada pelo ator Emil Jannings. 
A memória des-figurada de Walter Benjamin

Helano Jader Ribeiro

pelo. Só assim, por meio da abertura do nosso estado de exceção, é que poderá, também, ser possível a chegada do Messias. ${ }^{19}$

\section{A des-figuração [ent-stellung]: imagem e linguagem}

Walter Benjamin dificilmente teria delineado suas considerações sobre Proust, mais profusamente, sem o conceito freudiano de inconsciente: "Pois o que Benjamin expõe a respeito de Proust na forma da dimensão teórica-da-memória do esquecimento não seria compatível com um passado disponível"20 (WERNER, 2015, p. 93). No entanto, em "Sobre alguns motivos na obra de Baudelaire" aproxima-se em suas observações da teoria da memória com certa tensão, visto que "nas reflexões de Benjamin há também a dicotomia que predomina na teoria da memória de Freud entre a construção de cada memória e a inviolabilidade dos traços guardados inconscientemente do passado"21 (PETHES, [1999] apud WERNER, 2015, p. 93). Desse modo, sonho e memória proporcionam acesso a esses constructos, mas não podem dissolvê-los nas imagens originais de experiências de um tempo passado já vivido. O sonho se coloca, desse modo, como parte de uma teoria da recordação para Benjamin, assim sua Infância berlinense torna rastro possível de alcance do inconsciente.

As funções da memória em Infância berlinense são acionadas através de objetos e significantes adormecidos no inconsciente. Em alguns fragmentos retirados de Infância berlinense há uma presentificação de uma ausência pela traição da linguagem, a exemplo dos fragmentos "A Mummerehlen" e "Mercado". A linguagem cresce nesses excertos com a força de invocação da memó-

\footnotetext{
19 Como Benjamin explica, em nota de rodapé no Apêndice B do "Conceito de história", com base na Torá, aos judeus pouco importava o futuro, já que este não lhes era permitido. Benjamin retira o caráter mágico do futuro, do mistério e o atribui à presentificação da anamnese (Eingedenken). Somente nesse tempo anacrônico é que pode ser esperado o Messias. Há, desse modo, uma contraposição ao tempo homogêneo dos vencedores.

20 Denn was Benjamin in Form der erinnerungstheoretischen Dimension des Vergessens an Proust heranträgt, wäre nicht vereinbart mit einer verfügbaren Vergangenheit.

21 Daher findet sich auch in Benjamins Überlegungen jener Zwiespalt wieder, der in Freuds erinnerungstheoretischm Konzept zwischen der Konstruiertheit jeder Erinnerung und der Unantastbarkeit der unbewusst im Gedächtnis verwahrten Spuren der Vergangenheit herrscht.
} 
A memória des-figurada de Walter Benjamin

Helano Jader Ribeiro

ria, ao mesmo tempo em que jogos com significantes despertam nossa atenção para o momento em que a própria linguagem nos trapaceia:

Antes de mais nada, não pense que dizíamos Markt-Halle. Não, dizia-se Mark-Thalle, e como as duas palavras se tinham adulterado na rotina linguística, não conservando nenhuma delas o seu sentido original, assim também se adulteraram todas as imagens que se me ofereciam nas minhas andanças de rotina por esse mercado, de tal modo que nenhuma sugeria as acepções originais de comprar e vender.22 (BENJAMIN, 2013, p. 86-87).

A ideia preconcebida do passeio de uma criança com seus pais no mercado, em meio a compras de frutos, peixes, roupas, envoltos numa evocação de cheiros, perde lugar para fragmentos de cenas com mulheres, quase mitológicas "sacerdotisas da venal Ceres" (BENJAMIN, 2013, p. 87). Esses relatos não deixam de ser a impressão de um adulto, mas que, já fascinado pelas mulheres desde a infância, não consegue se render ao lugar-comum de um passeio no parque nos seus primeiros anos de vida. Além disso, a mudança das palavras Markt-Halle apenas intensifica o apelo pela memória. A mesma cena poderia ser chamada também de Marktfrauen ("mulheres do mercado"), e não nos admira a brincadeira com Mark-Thalle e a alusão direta ao consumo.

Em "A Mummerehlen" lemos: "Numa velha canção infantil aparece a Muhme Rehlen ${ }^{23}$. Como a palavra Muhme não me dizia nada, essa criatura transformou-se para mim num fantasma: a Mummerehlen" (BENJAMIN, 2013, p. 101). O uso linguístico original perde seu valor (mesmo que, para Benjamin, ele já não tivesse nenhum significado), desautorizando, dessa forma, o significado corrente de "tia Rehlen". Dessa nova palavra, quase inaudita, quase impronunciável, sobreviveu um significado outro, totalmente des-

22 Em nota, o tradutor João Barrento explica que Markt ("mercado") e Halle "pavilhão" seriam as formas linguísticas mais óbvias para se traduzir Markthalle. No entanto, Benjamin brinca sutilmente atribuindo o nome de moedas Mark (moeda alemã) + Thalle ["táler" ou também outro nome para uma moeda na Alemanha].

23 Muhme é uma palavra antiga para "tia” em alemão, e Rehlen, um nome próprio. 
A memória des-figurada de Walter Benjamin

Helano Jader Ribeiro

figurado, mas, somente assim, a imagem dessa memória poderia ser evocada.

Benjamin traduz, dessa forma, determinado conteúdo dos sonhos/memórias, problematizando-os pela linguagem literária, na qual são projetadas suas imagens de recordação. Esse procedimento não deve ser visto como simples representação das lembranças, mas como uma reviravolta na pseudonormalidade da linguagem através do surgimento dessas mesmas imagens.

Finalmente, talvez essa seja a grande investida de Walter Benjamin, o arqueólogo do instante: operar um jogo de escavação do passado entre memória, linguagem e sonho que consiga desestabilizar o presente enquanto totalidade e verdade. A linguagem surge, nessa lógica, menos como via de acesso do que como espaço de jogo [Spielraum]. Além disso, se é possível apontar para o presente enquanto falência de si mesmo, é porque essa agoridade cheia de história já está contaminada pelo passado. Esse mesmo presente vem des-figurado [ent-stellt] por uma profusão de imagens dialéticas, que são, portanto, pervivências [Nachleben] do passado, repletas de espacialidade-temporalidade.

\section{Referências}

BARRENTO, João. Limiares sobre Walter Benjamin. Florianópolis: Editora UFSC, 2013.

BENJAMIN, Walter. A imagem de Proust. In: BENJAMIN, Walter. Obras escolhidas. Magia e técnica, arte e política. Tradução Sérgio Paulo Rouanet. São Paulo: Ed. Brasiliense, 1996.

BENJAMIN, Walter. Passagens. Tradução Irene Aron e Cleonice Paes Barreto Mourão. Belo Horizonte: Ed. UFMG, Imprensa Oficial do Estado de São Paulo, 2006.

BENJAMIN, Walter. Rua de mão única. Infância Berlinense: 1900. Tradução João Barrento. Belo Horizonte: Autêntica, 2013. 
BENJAMIN, Walter. Sobre alguns motivos na obra de Baudelaire. In: BENJAMIN, Walter. Baudelaire e a modernidade. Tradução João Barrento. Belo Horizonte: Autêntica, 2015.

BENJAMIN, Walter. Sobre o conceito de história. In: BENJAMIN, Walter. $\mathbf{O}$ anjo da história. Tradução João Barrento. Belo Horizonte: Autêntica, 2013.

BENJAMIN, Walter. Escavar e recordar. In: BENJAMIN, Walter. Imagens de pensamento. Sobre o haxixe e outras drogas. Tradução João Barrento. Belo Horizonte: Autêntica, 2013.

DIDI-HUBERMAN, Georges. O que vemos, o que nos olha. Tradução Paulo Neves. São Paulo: Editora 34, 1998.

FREUD, Sigmund. O delírio e os sonhos na Gradiva. In: FREUD, Sigmund. Obras completas. Tradução Paulo Cézar de Souza. São Paulo: Companhia das Letras, v.8, 2015.

JAY, Martin. A imaginação dialética. História da Escola de Frankfurt e do Instituto de Pesquisas Sociais. Rio de Janeiro: Contraponto, 2008.

TIEDEMANN, Rolf. Studien zur Philosophie Walter Benjamins. Frankfurt: Suhrkamp, 1973.

WEIGEL, Sigrid. Entstellte Ähnlichkeit. Walter Benjamins theoretische Schreibweise. Frankfurt: Fischer, 1997.

WERNER, Nadine. Archäologie des Erinnerns. Sigmund Freund in Walter Benjamins Berliner Kindheit. Göttingen: Wallstein, 2015. 